\title{
LA FORMACIÓN POLÍTICA EN LA ESCUELA DEL ANTROPOCENO'
}

\section{POLITICAL FORMATION AT THE ANTHROPOCENE SCHOOL}

\section{A FORMACÃO POLÍTICA NA ESCOLA DO ANTROPOCENO}

\section{Edgar Arias Orozco ${ }^{2}$}

\section{Adriana Obando Aguirre ${ }^{3}$}

\section{Alejandra González Herrera ${ }^{4}$}

Corporación Universitaria Americana, Universidad de San Buenaventura Medellín

1 "Este documento constituye el problema de un proyecto de investigación sobre "Los retos de la formación política en la escuela del Antropoceno", y fue presentado como ponencia en el $5^{\circ}$ Encuentro Internacional de Pedagogía, Investigación y Experiencias Alternativas, realizado en Medellín entre el 8 y 10 de octubre de 2018; convocado y organizado por MOVA Centro de Innovación del Maestro y la Asociación de Institutores de Antioquia, ADIDA.

$2 \quad$ Magister en Educación. Docente Investigador Facultad de Educación Universidad de San Buenaventura Medellín. edgar.arias@usbmed.edu.co. ORCID: https://orcid.org/0000-0002-9884-840X. Google académico: https://scholar.google.com/ citations? user=SfCCqiYAAAAJ

3 Magister en Educación y desarrollo humano. Docente Facultad de Educación Universidad de San Buenaventura Medellín. adriana1212@gmail.com. ORCID: https://orcid.org/0000-0003-1987-7235 .Google académico: https://scholar.google.es/ citations? user $=Q Z$ tDmkAAAAJ\&hl=es

$4 \quad$ Magister en Educación. Docente Corporación Universitaria Americana, Correo:alejandragh326@gmail.com. ORCID:https://orcid.org/0000-0001-8122-4118. Google académico: https://scholar.google.es/citations?hl=es\&user=y2xc7y0AAA $\underline{A J}$ 
"Por primera vez se ha llegado a la creencia, entre quienes piensan el futuro a más de una década de distancia, que estamos jugando el final de una partida global. El control de la humanidad sobre el planeta carece de fuerza y es cada vez más débil. Damos palos de ciego, mal dirigidos, sin más objetivos que el crecimiento económico, el consumo sin límites, y la salud y la felicidad personales. Los miembros de nuestra especie se han convertido en los arquitectos y gobernantes de la era del Antropoceno".

\section{Edward Wilson}

\section{RESUMEN}

La nueva comprensión que propicia la mirada del Antropoceno propone desafíos profundos no sólo a los agentes de poder económico y político global, sino a toda la especie humana. En este contexto de transformación, se erige una relectura del papel de la escuela en la transmisión y discusión crítica sobre esta explicación de trascendencia mayor y la oportunidad de revisar los propósitos, sentidos y acciones de la formación política en el contexto escolar: ¿Cuál es el encargo que el Antropoceno hace a la escuela en su tarea formativa del sujeto político? ¿Puede la escuela aportar a la reflexión y análisis sobre la necesaria reorganización de las relaciones socionaturales en la perspectiva de contribuir, por lo menos, a una mayor sostenibilidad del planeta? La pregunta por la formación política en la escuela abarcaría hasta un cuestionamiento por el sentido mismo de la educación en la era del Antropoceno.

PALABRAS CLAVES: Antropoceno, formación política, escuela, naturaleza, educación.

\section{ABSTRACT}

The new understanding that fosters the gaze of the Anthropocene, poses profound challenges not only to the agents of global economic and political power, but to the entire human species. In this context of transformation, a rereading of the role of the school in the transmission and critical discussion on this explanation of greater transcendence and the opportunity to revise the purposes, Meanings and actions of political formation in the school context: What is the Anthropocene's task to the school in its formative task of the political subject? Can the school contribute to the reflection and analysis on the necessary reorganization of socio-natural relations in the perspective of contributing, at least, to a greater sustainability of the planet? The question of political formation in school would even involve a questioning of the very meaning of education in the age of the Anthropocene

KEYWORDS: Anthropocene, political education, school, nature, education

\section{SUMÁRIO}

A nova compreensão que propicia o olhar do Antropoceno, propõe desafios profundos não só aos agentes de poder econômico e político global, mas a toda a espécie humana. Neste contexto de transformação, ergue-se uma releitura do papel da escola na transmissão e discussão crítica sobre esta explicação de transcendência maior e a oportunidade de revisar os propósitos, sentidos e ações da formação política no contexto escolar: Qual é o encargo que o Antropoceno faz à escola em sua tarefa formativa do sujeito político? Pode a escola contribuir para a reflexão e análise sobre a necessária reorganização das relações socionaturais na perspectiva de contribuir, pelo menos, para uma maior sustentabilidade do planeta? A pergunta pela formação política na escola abrangeria até um questionamento 
pelo próprio sentido da educação na era do Antropoceno.

PALAVRAS CHAVES: Atropoceno, formação política, escola, natureza, educação

\section{INTRODUCCIÓN}

Actualmente, una de las discusiones científicas que ha cobrado relevancia global se da entre geólogos y científicos destinados a los ecosistemas y sistemas terrestres; se trata de una afirmación que ha venido determinando posturas acerca de la participación en una nueva era geológica llamada Antropoceno, en la cual los seres humanos han alcanzado un grado tal de colonización de la naturaleza que se está dejando atrás el Holoceno, situación que se hace visible en la influencia humana, pues es imprevisible en sus alcances, apelando a una recategorización de las relaciones entre ser humano y medio ambiente global (Arias, 2016, p. 795).

El artículo propone inicialmente una consideración acerca de la vigencia de la formación política en la escuela y de la necesidad de redimensionarla a la luz de los retos que expone el planteamiento teórico del Antropoceno. Se propone en segunda instancia una reflexión sobre la necesidad de una formación política que reconsidere no sólo las interacciones humanas, sino una nueva práctica política que vincule las relaciones socionaturales, las interacciones del ser humano con todos los seres vivos. Posteriormente se propone un análisis sobre las posibles integraciones de la formación política a diferentes áreas del conocimiento, y su articulación con fenómenos sociopolíticos que atraviesan el currículo escolar.

En los siguientes dos apartes se plantean reflexiones en torno a las posibles transformaciones de las subjetividades en procesos de formación política escolar que incorporen una inquietud por el Antropoceno, y por último se sugiere un planteamiento sobre la posibilidad que abre esta nueva categoría y perspectiva analítica de la crisis ambiental y climática para pensar nuevas formas de vida colectiva.

\section{LA VIGENCIA DE LA FORMACIÓN POLÍTICA}

Apelar al concepto de formación política sugiere de un lado la afirmación en la confianza de que el ser humano en su devenir tiene la capacidad de estar en constante desarrollo y progresión que le permite ser capaz de ver de otra manera, cada vez más abarcante, apuntando a algo que está más allá del desarrollo de capacidades y talentos (Gadamer (1991) citado por Ríos, 1996, p. 17).

Retomando a Zemelman (2002), se propone para esta reflexión asumir la formación política como el desarrollo de la capacidad del sujeto de colocarse ante las circunstancias en su condición histórica, capaz de construir sentidos, de asomarse a lo desconocido, de explorar lo no dado y concebir la historia desde el papel como sujeto. De tal modo que la concepción del otro como sujeto que se da forma así mismo, admite la afirmación del otro como sujeto existencial que tiene "capacidad de asombrarse y transformar el asombro en imperativo de conciencia y éste en necesidad de MUNDO", como sujeto con voluntad o capacidad para reconocer las opciones de sentido reconociendo espacios para ser sujeto.

La realidad, según Zemelman, ha de entenderse "no como simple externalidad sino como una constelación de ámbitos de sentidos posibles" (2002), en ella podemos ser fuerzas gestantes que transgreden los límites de los conceptos y renuevan contenidos, transforman lo indeterminado en horizontes contenidos en la cotidianidad. Zemelman afirma la necesidad de "aceptar que toda realidad es un espacio de posibilidades que, en tanto tal, conforma ámbitos 
diversos para ser activados por el propio sujeto" (2002).

La inaprehensibilidad de lo humano hace compleja una propuesta de formación política que no esté exenta de contradicción e incertidumbre. Sin embargo, el ser humano se ha debatido desde sus orígenes con las decisiones que aseguran la supervivencia del individuo, del grupo o de los otros, así, su trasegar posterior en los órdenes de la cultura evidencia que el homo sapiens ha debido desarrollar una significativa capacidad de cooperación para poder sobrevivir y de algún modo "dominar" el medio para habitarlo (Harari, 2014, p. 153). La cooperación como hecho irrefutable declara el germen de lo político desde las luchas por la sobrevivencia. Al asistir al Antropoceno se reedita y resignifica una inquietud acerca de cómo cooperar entre todos para continuar habitando la Tierra. Esta alarma es el principio de la pregunta sobre ¿cuáles son los sentidos y contenidos de la formación política para el Antropoceno en la escuela actual que tenemos?

Este texto se inscribe en una episteme prescriptiva, deseante y esperanzada en la capacidad humana de imaginar otros modos de cooperación; consciente de las limitaciones de nuestra especie en tanto animales racionales con una memoria determinante de la supervivencia y del poder, que a su vez ha reducido su capacidad racional y moral. Es posible, reconociendo la indeterminación de lo humano, su inacabamiento, sugerir un horizonte de formación política con propósitos que pueden ser puestos en discusión. Estas son pues ideas o sentimientos que pueden sopesarse en un diálogo que cobrará mayor relevancia cada que evidenciemos la degradación de lo vivo por la acción humana. El interés es destacar un asunto de la formación política que hoy podría proponerse a la escuela, se trata de pensar un fenómeno social y natural como eje de este propósito formativo: la formación para actuar en el Antropoceno.

\section{DEL ANTROPOCENTRISMO A UNA CONSIDERACIÓN DE TODO LO VIVO EN LA FORMACIÓN POLÍTICA}

Si en el centro de la política ha estado el ser humano ya sea para mejorar o para dañar su vida, así lo ha estado en la escuela de la modernidad. Hoy la perspectiva antropocéntrica no es un paradigma defendible en la política, la educación y la formación política. Para otra política, para otra educación, requerimos otra formación política que podría denominarse: formación política en la escuela del Antropoceno. Ya no pueden estar sólo los seres humanos en el centro de las ocupaciones políticas, deben estar los seres vivos, ha de estar la Tierra y su existencia como organismo vivo. De esto han sabido nuestros ancestros, y saben bastante nuestros pueblos indígenas, pero su conocimiento es subvalorado, no pertenece a la academia occidental y a la escuela que legamos (Uzendoski, 2015, p. 5).

$Y$ aunque pudiésemos afirmar que en la formación política en las escuelas ingresó hace un rato la Tierra y los seres vivos al incorporar el discurso del desarrollo sostenible, este es un discurso insuficiente para la dimensión del reto histórico y biológico que tenemos como especie. La prédica del desarrollo sostenible es limitada, sesgada, insuficiente, al considerar que un alineamiento con su contenido y propósito daría cuenta de un compromiso con la Tierra o la pervivencia de la naturaleza. Si hay algo por problematizar es la concepción de desarrollo que la escuela defiende explícita o implícitamente.

Aunque en el desarrollo sostenible se piensa en los seres vivos como parte de este todo que somos, el ser humano ocupa el lugar preponderante entre los otros seres vivos, en términos de su carácter de ser vivo con capacidad de adaptación agresiva para su 
sobrevivencia. No bastó que desde la década de 1970 la percepción de los problemas ambientales haya dejado de ser invocada como un asunto de competencia exclusiva de los Estados y haya pasado a considerarse un asunto de la humanidad, tampoco fue suficiente que la acumulación de evidencia científica respecto al impacto y responsabilidad de la acción humana sobre el medio ambiente (Franchini, Viola y Barros-Platiau, 2017, p. 179) para que se hubiese transformado una perspectiva del llamado desarrollo sostenible hacia apuestas más radicales de cambio del modelo económico depredador.

Entre tanto, la educación ambiental empezó a ocupar el interés en los Estados, como lo indican Medina y Páramo (2014):

En los últimos años ha aumentado la preocupación de la sociedad por el medio ambiente, gracias, en parte, a los acuerdos establecidos en el último cuarto del siglo XX, como la declaración de Educación Ambiental de Belgrado, la Conferencia de Río de Janeiro de 1992, la conferencia Río + 20, y la declaración del Decenio de las Naciones Unidas de la Educación para el Desarrollo Sostenible (2005-2014). En estos encuentros y cumbres internacionales, se adquirieron múltiples compromisos por parte de los Estados para redefinir sus programas, contemplando la variable ambiental, $y$ desarrollando estrategias efectivas de educación ambiental, como uno de los instrumentos para modificar sustancialmente la relación de la sociedad con la naturaleza. (p.19)

Surgieron iniciativas de distinto tipo a nivel gubernamental e intergubernamental, se crearon instituciones y dependencias estatales encargadas de asuntos ambientales, se han firmado acuerdos internacionales, se ha incorporado el tema del medio ambiente en agendas políticas y partidistas. Así mismo, en diferentes campos del saber se acrecentó la investigación científica y a nivel social se ha extendido una idea respecto de la responsabilidad que tenemos en el cuidado del medio ambiente. Todo ello no ha sido suficiente. "Las buenas intenciones" de Naciones Unidas que anidan en su discurso del desarrollo sostenible se estrellan hoy contra las nuevas evidencias científicas respecto al cambio climático, la disminución de la naturaleza virgen, la acidificación de los océanos, la pérdida de biodiversidad, los cambios en los ciclos naturales del agua, del nitrógeno y del fósforo, la pérdida del bosque amazónico, el aumento del extractivismo, la deforestación. Estas demostraciones permiten testificar una gran sospecha respecto a la pertinencia histórica del discurso del desarrollo sostenible, que no pone en cuestión la lógica de productividad del sistema económico.

Interpretando a Bruno Latur, para quien la ecología política ha fracasado, Innerarity plantea que "lo que ha ocurrido como consecuencia de las crisis ecológicas es que todas las oposiciones entre la naturaleza y la sociedad han perdido su función clarificadora" (2003, p. 322). Cita entonces a Latur:

El agujero de la capa de ozono es demasiado social y demasiado narrativo como para ser verdadera naturaleza, las estrategias de las empresas y los jefes de estado está demasiado referida a reacciones químicas como para que puedan ser reducidas solamente al poder y los intereses, el discurso de la eco-esfera es demasiado real y demasiado social como para disolverse completamente en efectos de significación (1993, p.14)

Quizás esta lectura respecto a las relaciones entre el poder y la crisis ecológica sea algo generosa y tolerante con las estrategias 
de reproducción de la máquina económica y política que tiene mayor responsabilidad en las afectaciones ambientales y del clima; sin embargo, ofrece nuevos elementos para incluir en un análisis sobre los postulados y mecanismos defendidos por los Estados respecto al desarrollo sostenible, la crisis ambiental y climática y las posibilidades de formación y acción política de los sujetos.

En la escuela se han desplegado similares discursos y propósitos respecto de la situación ambiental, sus problemáticas y dilemas. La escuela ha sido receptora de las comprensiones hegemónicas y dominantes sobre la oportunidad que para estas sociedades brindaría pensar y promover el desarrollo sostenible. Los Proyectos Ambientales Escolares $^{56}$-PRAE- han constituido el más explícito escenario de "aprendizaje" en torno a la incorporación de una reflexión ambiental en la escuela y han servido para que niños y jóvenes hagan apropiaciones conceptuales y prácticas conel propósito de hacercontribucionesamejoras ambientales. La fundamentación conceptual de los PRAE, la ofrece la Política Nacional de Educación Ambiental, donde se concibe que en el centro de la formación ciudadana responsable respecto al medio ambiente se encuentra contribuir con prácticas concretas al desarrollo sostenible. Este discurso que circula como un metarrelato sin cuestionamiento, se ha arraigado como verdad insustituible, irrebatible. De este modo, la educación ambiental en la escuela es una expresión de la funcionalidad de un supuesto discurso pro-ambientalista cuya finalidad es inofensiva a las relaciones de poder que granjean la crisis ambiental y climática.

La formación política en la escuela del

5

$6 \quad$ Los Proyectos Escolares Ambientales - PRAE son una estrategia planteada en la Política Nacional de Educación Ambiental del Sistema Nacional Ambiental - SINA, para la inclusión de la dimensión ambiental en la educación formal. Se concibe como un componente del Proyecto Educativo Institucional y un eje transversal del currículo de la educación básica.
Antropoceno no es educación ambiental, no se reduce a una acción pedagógica que sensibiliza, informa y ofrece elementos conceptuales sobre el medio ambiente y genera compromisos individuales para consumos más responsables y manejos adecuados de residuos sólidos, que pretende establecer compromisos para cuidar la naturaleza, etc. Puede conducir a todo lo anterior, que tiene relevancia social y cultural, pero no se reduce a ello. No consiste en un proyecto con objetivos y contenidos, estrategias, acciones y metodologías, como una pieza más del Proyecto Educativo Institucional o del currículo escolar.

El interés por apropiar el concepto de Antropoceno se sustenta desde las ciencias sociales y en la perspectiva que aquí se propone, en la necesidad de articular un conocimiento científico a una realidad que se hace cada vez más evidente: la capacidad destructiva que el ser humano ejerce sobre el planeta Tierra y las repercusiones que ello tiene para la pervivencia de los mismos seres humanos y de los demás seres vivos. De tal modo que el interés en términos de conocimiento, se traduce también en un interés ético - político, cuando tratamos de pensar la construcción de lo político en la escuela contemporánea.

Los debates científicos respecto a nombrar esta fase geológica como Antropoceno, así como los debates conceptuales respecto a su pertinencia y potencialidad en el ámbito de las ciencias sociales, constituyen fundamentos para la formación política de las nuevas generaciones en términos de las posibilidades que brindan como explicación e interpretación de las intenciones, los asuntos problemáticos y las perspectivas de la vida humana en el planeta y de la vinculación seres humanos - naturaleza.

Una intención urgente es la de pensar la acción colectiva e individual de los humanos en relación con las afectaciones que está sufriendo el planeta y sus ecosistemas por la acción humana. La formación emerge como una de las 
acciones que contribuyen al debate político y público, como camino factible para repensar la supervivencia humana, así como la dimensión moral del sujeto en un tiempo como el descrito.

Una formación política que asimila, aún en su proceso de discusión y debate, el concepto de Antropoceno como indicador de un fenómeno real, enfatiza en la reflexión respecto a reconocer y confrontar desde cada sujeto la responsabilidad con la administración de los sistemas terrestres. Esta formación política es para aprender a hablar sobre estos asuntos, para actuar y deliberar políticamente, para procesar el significado del concepto y las realidades que describe.

La formación política en la escuela del Antropoceno, ha de ocuparse de criticar el lenguaje y el discurso en torno al Antropoceno, pues cuando se habla de la intervención de la humanidad en la vida de la Tierra nos coloca a todos en la misma condición de responsabilidad, sin embargo, hay estructuras y relaciones de poder que condujeron a la crisis climática y ambiental.

Una de las hipótesis en discusión es que ha iniciado con la Segunda Guerra Mundial, por los ensayos y la detonación de las bombas atómicas (por los isótopos radiactivos: átomos transformados) que todos conocemos resulta de las disputas por el dominio de un orden geopolítico. Pero también está el planteamiento que señala cómo desde la Revolución Industrial la intervención destructiva sobre el planeta se intensificó, acompañada de la modificación radical de ecosistemas y formas de vida múltiple (Arias, 2016). El cambio climático resulta de una acción sistemática del ser humano, de estructuras y procesos de explotación y depredación del planeta en el marco de la intensificación del capitalismo. Han sido las sociedades occidentales, la idea de progreso, el llamado desarrollo, los mayores responsables del cambio climático, y de lo que da fundamento al Antropoceno. Los pueblos de África, Asia y América Latina tienen menor responsabilidad en esta depredación de lo vivo.

La propuesta más radical para una acción humana consecuente con una postura crítica ante el Antropoceno es la de pensar el postcapitalismo. Hacia allí ha de conducirse un ejercicio de formación política en la escuela, por ahora, no tanto para proponer una alternativa a esta sociedad depredatoria y desigual, sino para imaginar una forma de vida colectiva sustancialmente diferente a la que tenemos.

¿Cómo ayudamos a formar una significación de la Tierra, que nos comprometa con ella como un organismo vivo que nos cuida y nos posibilita la vida? Esta es la formación política mayor para hoy día.

\section{FORMAR POLÍTICAMENTE EN TODA PRÁCTICA PEDAGÓGICA}

Son muchos los objetivos, temas, problemas y contenidos que se planifican y abordan en el currículo escolar, en los planes de aula, en los planes anuales de cada institución educativa. La formación política no puede pensarse como un área o como una malla curricular adicional que está llena de contenidos, se estructura a cada paso, acción y momento de la vida escolar. Todo escenario, asignatura, actividad de clase o extracurricular son susceptibles de incorporar mensajes, signos, lenguajes, gestos, que pueden conllevar a preguntarse por las lógicas y sentidos con que habitamos esta nueva era llamada Antropoceno.

La formación política en torno a lo que estamos reconociendo como Antropoceno, nos conduciría inevitablemente a una reflexión crítica sobre el modo de desarrollo perverso que la humanidad se ha impuesto para el tipo de vida que tenemos, inundados de mercancías y consumo, pero con muchos humanos en la pobreza y la miseria. Formarse sujeto político alrededor de esta nueva comprensión del 
impacto en la Tierra, conllevaría a un profundo aprendizaje sobre recolocar la atención, volver la mirada atenta al organismo vivo que nos alimenta, es como volver a observar con atención lo que somos, la vida que cada uno es en la tierra. Exige además repensar la forma veloz en que transcurrimos, el afán en que andamos para innovar y producir, la celeridad que celebramos para llegar a un lugar impredecible, no dotado de sentido. Aprender a detenernos, para mirar con cuidado el entorno y el movimiento de la vida. Corresponde poner en evidencia el gran peligro que ha representado y representa para la vida de todos lo que hemos concebido como Desarrollo.

Así, la idea de una escuela destinada a pruebas para alcanzar logros académicos que supuestamente nos harán mejor la vida, ha de ponerse en cuestión, con determinación, responsabilidad y plena desconfianza sobre lo que se pretende lograr. La base de los resultados que se pretenden para la escuela, en un contexto neoliberal, pervive una defensa del tipo de desarrollo que hace inviable la vida, la justificación de lo mismo: del crecimiento económico como fin de toda acción humana. No hay ningún discurso de los representantes del poder multilateral que determinan la agenda educativa, que incorpore una sospecha, crítica, malestar, discurso problematizador del tipo de desarrollo dominante.

La formación política que se impone es una formación que nos convoca a ser humildes y aceptar que hemos estado equivocados. Es una formación para restar crédito a la arrogancia de todos los discursos, acciones y decisiones humanas que se empecinan en colocar los intereses humanos y en particular los de la acumulación de riqueza como el eje de la vida, de la existencia como seres vivos. El Antropoceno es el resultado de la aplicación sistemática y sin descanso de la razón instrumental sobre el planeta. El deseo de control y dominio de sus riquezas y diversidad ha estado en el centro de la relación interesada que el ser humano establece con la Tierra. El daño es inconmensurable.

Es una formación política que nos seduzca para cambiar de actitudes, de prácticas, y estilos de vida. Ello implica el reconocimiento de los límites para desear. La $4^{\text {a }}$ revolución industrial puede no contemplar estos límites, el alcance irresponsable de la ambición o puede ser una gran oportunidad para ofrecer soluciones y alternativas frente al uso de las energías, el agua, la Tierra y sus minerales. Sin embargo, la tecnología no alcanza para ganar una proyección prometedora de la sostenibilidad del planeta. Requerimos transformar nuestro modo de relacionarnos con la Tierra y la naturaleza, con sus recursos y riquezas, pu nuestra manera de vida colectiva que no se cansa de producir mercancías y basuras.

La nueva formación política requiere de aprender sobre la biología y la naturaleza, pues en ellas obtendremos muchas respuestas y soluciones a preguntas y daños que hemos hecho a la vida en sus múltiples formas de presentarse. La nueva formación política es una formación para repensar la vida. Así pues, la formación política en la escuela ha de echar mano de las ciencias naturales, de la biología, de la historia, de la antropología, de las tecnologías, de la filosofía, del arte, de las matemáticas, del lenguaje, de la química, de todos los recursos del conocimiento, para ofrecer una nueva perspectiva de lo político que involucra el todo, la totalidad de la vida y de nuestro lugar de especie humana. De tal modo que una práctica educativa consecuente con esta perspectiva, por ejemplo, será aquella que enseñe cómo una huerta casera puede ser un acto de rebeldía y una acción política responsable que involucra la vida del ser humano que siembra para contribuir a su salud, sin afectar la vida de otros seres vivos o sin contaminar diversos ecosistemas. Ya no se trata de sensibilizarnos frente al medio 
ambiente o de ser cuidadosos de las plantas, se trata de comprender el hecho político del Antropoceno, el hecho político de cada decisión de consumo, de cada decisión que elige a quienes nos gobiernan, de cada decisión sobre la apropiación y uso de la Tierra.

Esta formación política que se propone, implica repensar nuestras nociones del tiempo, no se trata de entender el futuro inmediato de sí mismos, se trata de asumir que somos responsables del futuro de otros, de otros que no conoceremos, pero que quizás serán nuestros descendientes, y aun no siéndolo, son parte de la vida que nos corresponde defender sin reserva. Pero, asimilar este periodo geológico como Antropoceno nos conmina también a considerar nuestras comprensiones sobre las huellas que como humanos marcamos sobre la Tierra, es decir, que nos conduce a contemplar las marcas de nuestra acción sobre la memoria. Corresponde hacer una memoria de la responsabilidad humana sobre el Antropoceno, bien sea para mirar críticamente el papel que jugamos como seres vivos en la producción o destrucción de la vida, o para hacer consciencia acerca de cómo la Tierra se ha inscrito en nuestros cuerpos, relaciones, modos de vida colectiva, formas de desear, decisiones y procesos de constitución de lo social, lo económico y lo político.

Es hacer una memoria del Nosotros en relación con la Tierra, no sería sólo utilizar la producción de explicaciones científicas acerca de las acciones humanas y sus impactos sobre el planeta para intentar transformaciones en los modos de habitar el mundo, sino para hacer un nuevo relato sobre la experiencia humana, una nueva narrativa sobre nuestro paso por la vida. Es una memoria de la especie. Así como en la formación política tradicional se intenta ofrecer descripciones, conceptos y métodos de interpretación de las relaciones de poder entre humanos como pasado histórico y pocas veces como memoria, precisamos igualmente de una formación política que repare sobre nuestra memoria como especie en tanto visualización, recordación y resignificación de lo que hemos hecho sobre la Tierra como organismo vivo, parte de ella, seres vivos surgidos, reproducidos y muertos en ella.

Esta es una memoria que nos lleve a establecer de otro modo la experiencia de lo vivo, de la biodiversidad, la experiencia de ser parte de la Tierra. Es quizás una buena oportunidad para resignificar una sensibilidad respecto del Otro humano próximo, ya no sólo como parte de un entramado de relaciones de poder, sino como parte de mí.

Así pues, la formación política en la escuela del Antropoceno, compromete un esfuerzo respecto en pensar cómo decisiones individuales cotidianas modifican la vida de los otros y del planeta, de tal modo que por ejemplo asumamos una responsabilidad con la huella de carbono -cantidad de emisiones de gases de efecto invernadero- que cada uno generamos.

Concita al pensamiento crítico sobre el papel que ejercen estructuras de poder político ancladas en la modernidad, que todavía conciben la reproducción social y material de la especie como una acción sistemática y sin fin sobre el planeta. Ello necesariamente obliga a una lectura crítica de la economía depredatoria que presiona la producción de contaminación y el consumo humano. La formación política en la escuela del Antropoceno sugiere que se configuren miradas críticas sobre quienes quieren y detentan el poder político estatal y sobre quienes los patrocinan y apoyan en sus intenciones de alcanzar el poder.

Reducir la adquisición y uso de productos, reutilizar y reciclar, siendo acciones consecuentes con una consciencia crítica sobre el cambio climático, no son suficientes y pueden terminar siendo ingenuas para trazar 
un cuestionamiento oportuno a las estructuras de poder global que generan las condiciones políticas y económicas para hacer imposible la sostenibilidad del planeta. Entender que la pérdida de biodiversidad se debe a la destrucción de los hábitats naturales, debe conllevar a una formación de la reflexión política no sólo para animarla a descalificar esta acción humana de manera general, sino a tratar de propiciar comprensión en los niños, niñas y jóvenes sobre las decisiones políticas y económicas que condujeron a la pérdida de los hábitats y las responsabilidades específicas de los agentes de poder en este hecho.

Así mismo, leer atentamente y con espíritu crítico el proceso de fragmentación de los hábitats que coloca barreras a las diversas especies por la construcción de autopistas, campos de cultivo, urbanización acelerada, conduce a pensar quiénes, cómo y por qué toman decisiones sobre las formas en que se usa el suelo urbano, la otorgación de licencias ambientales para la explotación de recursos naturales, la ampliación de zonas de exploración y explotación minera, la cesión de cuencas hidrográficas y de zonas ambientales protegidas para el extractivismo (recientemente la gobernación del Guainía otorgó permisos a una multinacional canadiense para explorar y proyectar explotación de coltán en extensiones significativas de su territorio).

De otro lado, la formación política hoy exige debatir los efectos del crecimiento de la devastación forestal a cambio de más ganado y mayor producción de aceite de palma, por ejemplo, y contribuir a comprender el tipo de intereses económicos y políticos que mueven al Estado y a las instituciones responsables a ceder poder y a no ejercer el control y la responsabilidad política necesarios para evitar o impedir la depredación de tierras y recursos fundamentales para nuestra pervivencia futura.
No sería consecuente con una mirada crítica del Antropoceno, enseñar química sin destacar el profundo daño al que conduce la especialización de esta área de conocimiento que se destina a producir sustancias contaminantes para la agricultura industrial (fertilizantes, pesticidas, sustancias farmacológicas), los contaminantes químicos presentes en los alimentos, los contaminantes ambientales, etc. Así pues, no se trataría solo de que los jóvenes aprendan química, sino de contextualizar el uso de la química en la configuración de la sociedad de mercado y las responsabilidades y responsables de su mal uso. Si enseñamos ciencias naturales o economía, cómo no referirnos a las repercusiones que sobre la Tierra tienen las 45 mil presas que hay en el planeta y que retienen el flujo fluvial de miles de ríos.

Entre las consecuencias de asumir la formación política considerando la responsabilidad humana por el Antropoceno, está la de identificar los actores de poder político, económico e ideológico que se benefician con estas decisiones utilizando las estructuras e institucionalidad estatal y gubernamental, los medios de comunicación, los mecanismos masivos de reproducción ideológica -redes sociales- para inducir al sostenimiento de una perspectiva del desarrollo que ha demostrado ser depredatoria y profundamente irresponsable con la Tierra y la vida.

Los textos escolares han de sufrir vastas transformaciones en sus propósitos, contenidos, información, diseños, materiales y usos. En este sentido, la formación política es un ejercicio constante por parte del sujeto político, en todo momento y en cada relación. La realidad antropológica, biológica, geológica y política del Antropoceno, demanda de la escuela una revisión crítica de los currículos: ¿qué contenidos son susceptibles de revisión crítica, de replanteamientos en su enfoque y uso? ¿qué temas y contenidos que aún no aparecen, 
requieren incorporarse con urgencia? ¿qué perspectivas teóricas se defienden respecto del valor y papel de la ciencia y la tecnología en el mundo contemporáneo y de qué manera inscriben una lectura crítica respecto a su lugar en el Antropoceno?

Podemos imaginar una revisión del abordaje de la historia y el devenir humano, que revalore la comprensión, desde una socioantropología, del papel del homo sapiens en la vida biológica y en la cultura, así como de las posibilidades que se tienen para actuar políticamente ya no en función de una ideología para el ser humano, sino en función de una política para la vida del planeta, en dirección de una política que involucre las necesidades de los otros seres vivos, en suma, una mirada socionatural de la política.

\section{LAS SUBJETIVIDADES SE CONFRONTAN EN LA FORMACIÓN POLÍTICA}

La formación política en la escuela del Antropoceno no está direccionada a generar capacidades reflexivas y acciones para hacer sostenible la economía capitalista y a su vez el planeta. Debe pensar precisamente la gran contradicción que reviste cualquier intento de educación ambiental hacia la sostenibilidad sin poner bajo sospecha la estructura económica en gran parte responsable de la crisis ambiental. Por ello, una decisión aplicada a propiciar dicha formación política, demanda a su vez una observación de sí y una problematización y transformación de las formas de fabricación del deseo en la sociedad capitalista. Es la oportunidad para imaginar otra manera de estar juntos y con la Tierra.

El sujeto de conocimiento escolar puede proveerse, a través de la formación política, de nuevas herramientas comprensivas acerca de las relaciones entre sus deseos, decisiones y prácticas concretas que adelanta cotidianamente para operar sus responsabilidades, intereses y necesidades. Las relaciones con el mercado y el consumo, la elección de mercancías, la adquisición y uso de tecnologías, la utilización de fuentes de energía; las preferencias por modas, ropas y artefactos; las opciones en los usos de los medios de transporte particular y público, más o menos contaminantes; las formas de relacionamiento con las mascotas y demás especies animales; las valoraciones de la naturaleza, las plantas y la vegetación; los hábitos alimenticios y la compra y venta de alimentos; las interacciones entre sociedades de alto consumo y sociedades con capacidades de consumos medios y bajos; la utilización de los recursos naturales no renovables, el consumo de agua, la producción agrícola y la expansión de la frontera agrícola en desmedro de ecosistemas de bosques y selvas; los sentidos del conocimiento humano y del desarrollo tecnológico; son algunos de los muchos asuntos que podrían constituirse objeto de análisis en procesos de formación política enmarcados en una pregunta por el Antropoceno y sus retos políticos, antropológicos y sociológicos, entre otros.

La escuela es un escenario indicado para movilizar la inquietud por la acción individual y colectiva en torno los desafíos que impone el cambio climático y todas las realidades referidas al declive de los ecosistemas terrestres. Es en ella donde niños, niñas y jóvenes pueden inaugurar sensibilidades y pensamiento crítico respecto a las transformaciones profundas y desfavorables del medio ambiente para muchas especies vivas, entre ellas los sapiens. Diferentes países del mundo se han declarado en Emergencia Climática y Ecológica para incorporar decisiones de distinto tipo a las agendas políticas, económicas y sociales de los gobernantes. La escuela y los procesos de formación política que ya adelante o busque emprender, podrían dirigirse al incremento de voluntades, compromisos y acciones que permitan reconocer y valorar críticamente 
las múltiples acciones que, a nivel de grupos humanos, comunidades, ciudades, países o regiones vienen adelantándose para revisar modos de producción y consumo, estilos de vida, procesamiento de residuos sólidos, apropiaciones y usos de recursos naturales, etc.

Niños, niñas y jóvenes vienen liderando en el mundo distintas iniciativas para reclamar decisiones y acciones contundentes por parte de gobernantes, agentes económicos y financieros frente al cambio climático. Greta Thunberg $^{7}$ se ha erigido en un ícono de las voces más jóvenes en la movilización global contra las acciones humanas que han conducido a la crisis del clima. En un libro ${ }^{8}$ que recoge sus declaraciones y discursos en diferentes escenarios políticos multilaterales y en algunas grandes movilizaciones estudiantiles, Greta se pregunta:

¿Y por qué debería estar estudiando por un futuro que pronto podría dejar de existir cuando nadie está haciendo absolutamente nada por salvarlo? Además, ¿qué sentido tiene aprender datos dentro del sistema educativo cuando es evidente que los datos más importantes que nos proporciona la ciencia más erudita dentro de ese mismo sistema educativo no significan nada para nuestros políticos y para nuestra sociedad? (p. 20)

De esta manera, Greta Thunberg coloca a la escuela una pregunta sobre el sentido político de la educación: ¿y si el conocimiento obtenido no deriva en acción política, especialmente cuando se trata de la supervivencia humana y de la vida en el planeta, entonces qué importancia tiene "educarse"? Ahora bien, Paulo Freire consideró la necesidad de una educación esperanzadora que posibilitase transformaciones políticas y

$7 \quad$ Joven activista sueca contra el cambio climático. 8 Thunberg, Greta (2019). Cambiemos el mundo. \#Huelga por el clima. Bogotá: Penguin Random House Grupo Editorial culturales (Chaustre, 2007). Entre el escepticismo de Thunberg respecto de la inacción humana y la apuesta de Freire, la formación política en la escuela del Antropoceno exige redimensionar el significado de la esperanza, su potencia movilizadora y su fuerza política. La formación política en la escuela ha de trascender la intencionalidad de la formación democrática y ciudadana hacia una crítica radical del papel que la cultura, la sociedad y el mercado han cumplido en la configuración del Antropoceno y hacia acciones posibles desde los sujetos y los colectivos sociales dentro y fuera del espacio escolar.

El tipo de formación política que necesitamos ha de buscar transformar nuestras actitudes cotidianas frente a los consumos, los deseos, las necesidades, las ambiciones, las modas, los recursos de que echamos mano para hacernos reconocer y que son irresponsables con la pervivencia de lo vivo. La transformación de actitudes no está exenta de múltiples dificultades, pero es fundamental decirlo, insistirlo y creérnoslo.

La acción política en la escuela de hoy supone apostar a la confianza en que podemos tener actitudes consecuentes con la vida, como sujetos individuales y como colectivos humanos, que podemos vivir cotidianamente sintiéndonos unidos o parte de la naturaleza, de la Tierra, que éstas no están para nuestro servicio, que las decisiones políticas no pueden ser simplemente para saber cómo aprovechamos la enorme riqueza que nos provee la Tierra para ponerla a nuestro servicio, sino que estas decisiones han de contemplar la red que es la naturaleza, y las formas como podemos contribuir a ese tejido, no las formas como podemos dañarlo, las formas como podemos reafirmar que hacemos parte de la Tierra, de la naturaleza, entender que somos el medioambiente.

Se requiere contribuir a entender el mundo en el que vivimos y lo que hemos hecho 
los humanos en éste, las afectaciones que hemos causado a la Tierra. Creer que pequeñas actitudes que transformen, son un aporte grande y valioso. Una formación política que nos ayude a sentir la naturaleza, a hacer un cuestionamiento fundamental a la idea de que la explotación de la naturaleza puede ser sostenible, de que son reversibles algunos de los efectos perversos que la acción humana produce en ella.

\section{IMAGINAR OTRAS FORMAS DE VIDA COLECTIVA EN EL ANTROPOCENO}

Sin todavía conquistar una escuela democrática, apegada a los mínimos que propuso la Constitución de 1991 y la ley 115 de 1994 o Ley General de Educación, nos aproximamos a un escenario más exigente políticamente, con mayor alcance y demanda en la reflexividad y en la voluntad transformadora; es necesaria una formación política que propicie reflexión y crítica respecto de las posibilidades de la democracia en la geopolítica global para la constitución de acuerdos y acciones respecto a los desafíos de la humanidad en el Antropoceno.

Al plantear que la formación política exige pensamiento crítico, se ratifica la necesidad de un pensamiento y una reflexión política que descubra los intereses, los agenciamientos del poder, las prácticas de dominación que conducen a la autoexplotación humana y a relaciones de desigualdad económica y política. Son retos mayores, ¿cómo transitar a una formación política en la escuela que no abandone el empeño por la democratización de las relaciones en el microespacio político, que reconozca los desafíos planteados a la democracia formal por las situaciones estructurales de pobreza y desigualdad y por las formas autoritarias del poder ancladas en la violencia política y que a su vez se ocupe de pensar y promover acciones respecto a la amenaza que se cierne sobre la pervivencia de los humanos en la Tierra y los demás problemas que nos plantea el Antropoceno? ¿Cómo dar lugar en la escuela a una formación política que se proponga integrar el análisis y conocimiento del Antropoceno o de los graves problemas que han desestabilizado el planeta, de tal forma que se reconozca su urgencia e importancia?

Sugiere Arias lo siguiente:

La política de la naturaleza no puede escapar a la naturaleza de la política: formular una respuesta a la desestabilización planetaria exige conciliar intereses y puntos de vista que no se concilian fácilmente. Máxime cuando el objeto de la acción política presenta, en este caso, unos rasgos tan desacostumbrados: temporalidad profunda, escala geológica, causalidad compleja. Si durante milenios hemos concebido los regímenes políticos como asuntos intrahumanos, el Antropoceno nos obligaría a embarcarnos en una profunda reconceptualización de la democracia y la agencia política. Pero ¿acaso es posible democratizar el Antropoceno? ¿Podemos dar forma a una democracia ecológica cuyo objeto sean las relaciones socionaturales de la nueva época? (p. 188)

Su afirmación y sus preguntas proponen aún más encrucijadas a las probabilidades de una formación política en la escuela que incorpore una lectura urgente del Antropoceno y sus implicaciones para la vida planetaria y para la democracia en el mundo. Aun así, también insinúa Arias la validez y necesidad de una resignificación de lo político y de la democracia, no sólo para saber cómo vivir en las nuevas y complejas realidades ecoambientales, sino también para imaginarnos una democracia ecológica que se proponga no sólo una mirada y unas formas de actuar desde los humanos para los humanos, sino también desde los humanos para los otros seres vivos, para la naturaleza, 
diferente a solo una preocupación por el desarrollo sostenible.

La riqueza de una pregunta y una reflexión sobre el Antropoceno en la base de procesos de formación política en la escuela consiste también en la posibilidad de movilizar el pensamiento y el conocimiento, la imaginación y la voluntad, el compromiso y la fuerza de la agencia humana hacia tratar de responder: ¿a qué otra forma de vida colectiva aspirar? ¿a qué tipo de experiencia humana y socionatural dirigirnos con las capacidades que hemos alcanzado como humanidad? ¿qué posibles rupturas con las estructuras de exclusión, dominación, desigualdad social y pobreza nos propone una relectura crítica de lo hecho por los sapiens en miles de años de evolución o en cientos de años del capitalismo? En estas preguntas anida quizás la mayor justificación respecto de la necesidad de pensar la formación política en la escuela del Antropoceno.

\section{CONCLUSIONES}

Aunque todavía los geólogos y científicos no terminan de acordar la validez de la hipótesis del Antropoceno, éste concepto "ha proporcionado aval científico a una intuición compartida acerca del estado de las relaciones naturales y ha servido como marco general para su discusión" (Arias, 2018, p.18). La escuela no puede desentenderse de este importante progreso teórico, sus connotaciones demandan una revisión crítica de los sentidos de la formación y de la adquisición de saberes académicos. Un examen crítico de los esfuerzos educativos en la escuela básica y hasta en la superior, muy probablemente, nos demostrará una ausencia alarmante de una intención por comprender pedagógicamente las afectaciones estructurales en los modos de vida humana que trae consigo la crisis ambiental y climática, la deforestación depredadora, la pérdida sistemática de especies vivas y la aniquilación de múltiples ecosistemas terrestres, entre otras graves situaciones.
¿Cómo incorporar a los fines y diseños curriculares una pregunta por las repercusiones del Antropoceno en el presente y futuro humanos? No se trataría sólo de incluir en un conjunto de contenidos y temas lo que significa y sugiere cultural y políticamente el concepto del Antropoceno, no consistiría exclusivamente en agendar, como otro asunto para memorizar y evaluar, lo que de profundidad antropológica, sociológica, biológica y política traza dicha categoría. La escuela, la educación y la pedagogía tienen que aplicarse a pensar y redefinir los horizontes de la formación humana y social.

Dice Arias (2018):

Tal como apunta el paleontólogo Valentí Rull, no es necesario definir formalmente el Antropoceno como una época geológica para aceptar que la actividad humana ha cambiado los procesos del sistema terrestre de manera significativa durante los últimos siglos; tampoco para reflexionar sobre las implicaciones morales y políticas de esa profunda alteración. (p. 17)

La urgencia y necesidad de reflexionar en las implicaciones morales y políticas de la acción humana sobre los ecosistemas terrestres, nos induce obligatoriamente a resituar la discusión sobre la formación política en la escuela, a destacar nuevas intencionalidades y estrategias para recrear una crítica y una acción ecohumana posible respecto del modo de vida y subjetivación que la sociedad capitalista instauró (individualismo, consumismo, exacerbación del narcisismo), respecto de las crecientes formas de profundización de la desigualdad social y de las formas de colocación del ser humano en la razón instrumental y en la relación de dominación con la naturaleza (explotación, depredación, desconocimiento, antropocentrismo, etc.). 
Los numerosos conflictos sociales que se vienen produciendo a causa de la crisis ambiental y climática en diversas regiones del mundo, proyectan en el tiempo imágenes de multiplicación de mayores conflictos, que muy probablemente se presentarán en las sociedades y países más desiguales y con mayores condiciones de pobreza. Esta evidencia y prospectiva conllevan a plantear que la formación política habrá de conducirse hacia la mejora de las capacidades, herramientas y procedimientos para el tratamiento de conflictos, así como hacia la imaginación y creación de estrategias políticas y económicas que provean a las personas y grupos humanos de garantías de protección de sus vidas y de reproducción material y social dignas.

La formación política en la escuela del Antropoceno no consiste en una labor destinada a ofrecer información y desarrollar capacidades o competencias ciudadanas, no radica en transmitir el legado de la modernidad política y los avatares y posibilidades de la democracia. Constituye una práctica, una experiencia, un devenir reflexivo respecto del lugar que ocupamos y la responsabilidad que tenemos como seres vivos, sapiens, humanos, sujetos con capacidad de acción y pensamiento, en relación con la vida en la Tierra, no sólo la vida de los humanos, la vida del planeta como un organismo, no porque la Tierra nos requiera y dependa de nuestras decisiones, sino porque requerimos de una afirmación de nuestro vínculo con el lugar que nos permite nacer, respirar y morir, y porque en nuestro acumulado histórico hemos aprendido que es posible pensar y hacer por la vida de los que siguen después de que no estemos.

\section{BIBLIOGRAFÍA}

Arias, M. (2018). Antropoceno: La política en la era humana. ( $1^{\mathrm{a}}$ ed.). Bogotá: Penguin Random House Grupo Editorial

Arias, M. (2016). El giro antropocénico. Sociedad y medio ambiente en la era global. Política y sociedad, 53 (3), pp. 795 - 814. Recuperado de: http://dx.doi.org/10.5209/rev_ POSO.2016.v53.n3.49508

Calixto, R. (2012). Investigación en educación ambiental. Revista Mexicana de Investigación Educativa - RMIE, VOL. 17, NÚM. 55, PP. 10191033. Recuperado de: http://www.scielo.org.mx/ pdf/rmie/v17n55/v17n55a2.pdf

Chaustre, Alvaro (2007). Educación, política y escuela desde Freire y las pedagogías críticas. Revista Educación y Ciudad, No. 12, pp. 99 115. Recuperado de:

- www.idep.edu.co/revistas/index. php/educacion-y ciudad/article/ download/180/169/

Franchini, M., Viola, E. y Barros-Platiau, A. (2017). Los desafíos del Antropoceno: de la política ambiental internacional hacia la gobernanza global. Ambiente \& Sociedade $n$ São Paulo v. $X X$, n. 3 n p. 179-206. Recuperado de:http:// www.scielo.br/pdf/asoc/v20n3/es 1809-4422asoc-20-03-00177.pdf

Harari, Y. (2014). De animales a dioses. Breve historia de la humanidad. Bogotá: Penguin Random House - Debate.

Innerarity. D. (2003). Políticas de la naturaleza en la sociedad del conocimiento. Revista de Estudios Políticos, 122, 317-329

Medina, I., y Pablo, P. (2014). La investigación en educación ambiental en América Latina: un análisis bibliométrico. Revista Colombiana de Educación, 66, pp. 55-72. Recuperado de: 
- www.scielo.org.co/pdf/rcde/n66/ n66a03.pdf

Ministerio de Medio Ambiente y Desarrollo Sostenible (2016). Los proyectos ambientales escolares -PRAE en Colombia: Viveros de la nueva ciudadanía ambiental de un país que se construye en el escenario del posconflicto y la paz.

Ministerio del Medio Ambiente y Ministerio de Educación Nacional (2002). Política Nacional de Educación Ambiental SINA. Recuperado de:http://cmap.upb.edu.co/ rid=1195259861703_152904399_919/politi-ca educacion_amb.pdf

Ríos, C. (1996). Un acercamiento al concepto de formación en Gadamer. Revista Educación y Pedagogía, vol. 7, núms. 14-15, pp. 15-35. Recuperado de: http://ayura.udea.edu.co:8080/jspui/ bitstream/123456789/2824/1/RiosClara_1995_ acercamientoconceptoformaciongadamer.pdf

Thunberg, G. (2019). Cambiemos el mundo: \#Huelga por el clima. (1a ed.). Bogotá: LumenZemelman, Hugo (2002). Necesidad de Conciencia. Un modo de construir conocimiento. Barcelona: Anthropos Editorial.

Uzendoski, M. (2015). Los saberes ancestrales en la era del antropoceno: hacia una teoría de textualidad alternativa de los pueblos originarios de la amazonia. Rev. Investig. Altoandin. Vol 17, $\mathrm{N}^{\circ} 1$, pp. $5-16$ Recuperado de: https://www.researchgate. net/publication/281640085 los saberes ancestrales_en_la_era_del_antropoceno hacia_una_teoria_de textualidad_alternativa_ de los pueblos originarios de la_amazonia 